\title{
Peran Akademisi Dalam Memajukan UKM Wajik Tapai Melayu
}

\author{
Sri Maryanti*1, Nining Sudiar², Afred Suci ${ }^{3}$, Hardi ${ }^{4}$ \\ 1,3,4Fakultas Ekonomi, Universitas Lancang Kuning \\ ${ }^{2}$ Fakultas Ilmu Budaya, Universitas Lancang Kuning \\ *e-mail: ssrimaryanti@yahoo.com ${ }^{1}$
}

\begin{abstract}
The purpose of this community service activity scheme for the Regional Superior Product Development Program is to overcome the problem of the Malay tapai partner since 2008, namely the texture of the prouduk that hardens before expiration, the processing process is still conventional and the packaging process is inefficient and ineffective. This greatly affects the efforts of PPPUD partners in advancing their business. The methods used are training, mentoring and activity evaluation. The result of this activity is that the texture of the tapai Malay diamond is softer and more durable using Stabilex BR. The processing process is more efficient because partners use a crystallization evaporator which can save 3 hours with the same quantity of dough. The packaging of tapai malay diamonds has undergone a more contemporary change and shortens the time in the packaging and consumption process in the minds of consumers. This PPPUD activity is very beneficial for partners, it is proven that the problems faced by PPPUD partners can be resolved properly, this is the important role of academics in advancing SMEs.
\end{abstract}

Keywords: UNILAK Academics, UKM Assistance, Training, PPPUD Partner Evaluation

\begin{abstract}
Abstrak
Tujuan kegiatan pengabdian kepada masyarakat skim Program Pengembangan Produk Unggulan Daerah ini adalah untuk mengatasi maslah mitra wajik tapai melayu sejak tahun 2008 yaitu tekstur prouduk yang mudah mengeras sebelum habis masa kadaluarsa, proses pengolahan yang masih konvesional dan proses pengemasan yang tidak efisien dan efektif. Ini sangat berpengaruh terhadap usaha dari mitra PPPUD dalam memajukan usahanya. Metode yang digunakan adalah pelatihan, pendampingan dan evaluasi kegiatan.Hasil dari kegiatan ini tekstur produk wajik tapai melayu lebih lembut dan tahan lama dengan menggunakan Stabilex BR. Proses pengolahan lebih efisien karena mitra menggunakan mesin Evaporator Kristalisasi yang mampun menghemat waktu 3 jam dengan kuantitas adonan yang sama. Kemasan dari wajik tapai melayu mengalami perubahan lebih kekinian dan lebih mempersingkat waktu dalam proses pengemasan dan konsumsi di angan konsumen.Kegiatan PPPUD ini sangat besar manfaatnya bagi mitra terbukti maslaha yang dihadapi oleh mitra PPPUD dapat teratasi dengan baik, inilah pentingnya peran akademisi dalam memajukan UKM.
\end{abstract}

Kata kunci: Akademisi UNILAK,Pendampingan UKM, Pelatihan, Evaluasi Mitra PPPUD

\section{PENDAHULUAN}

Dunia akademisi sangat sarat dengan kegiatan seperti pelaksanaan tri dharma perguruan tinggi melalui kegiatan Pengabdian Kepada Masyarakat (PKM). Didalam buku panduan penelitian dan pkm edisi XII dinyatakan bahwa fokus utama dari kegiatan PKM salah satunya adalah memberikan solusi berdasarkan kajian akademik atas kebutuhan, tantangan, atau persoalan yang dihdapi masyarakat, baik secara langsung maupun tidak langsung . Peran akademisi dalam memajukan usaha dari UKM yang ada memang sangat diharapkan oleh UKM mengingat UKM juga memiliki ketebatasan dalam memajukan usaha mereka. Usaha Wajik Tapai Melayu telah lama dirintis sejak tahun 2008 namun sebelum adanya akademisi yang turut membantu UKM Wajik Tapai Melayu ini rata-rata pola pemasaran untuk produk masih menggunakan direct selling hal ini dilakukan oleh mtra karena produk yang dihasilkan tidak bertahan lama sehingga harus memperhitungan waktu pengantaran produk ke toko-toko.

Produk wajik tapai melayu bisa bertahan selama 1 (satu) bulan jika lebih dari itu tekstur wajik tapai akan mengeras walalupun produk tersebut masih layak konsumsi namun karena memiliki tekstur yang keras sehingga konsumen enggan untuk membelinya. Disamping itu 
dalam proses pengolahan produk wajik tapai melayu harus dilakukan dengan cara konvensional, dimana pekerja harus melakukan pengadukan adonan dalam waktu 5 jam dengan kapasitas adonan $6 \mathrm{~kg}$ yang saat dikemas menghasilkan 3,5 kg adonan wajik tapai, dalam prosesnya mitra masih mengguanakan kompor yang berbahan bakar minyak tanah untuk proses pengadukan adoanan. Sehingga mitra harus mempersiapkan satu hari untuk proses pembuatan sedangkan hasil olahan wajik yang telah diolah harus dikemas untuk dijual dan pengemasan produk cukup menyita banyak waktu karena harus menempuh 5 (lima) tahapan dalam mengemas produk wajik tapai melayu, kegiatan ini berlangsung cukup lama sejak tahun 2008 - 2018 bisa dianalisis berapa tingakat kerugian dari mitra , baik kerugian dari sisi financial maupun non financial. Oleh karena itu sejak tim akademisi Universitas Lancang Kuning ikut ambil andil untuk memajukan usaha mitra wajik tapai melayu melalui kegiatan PKM pada skim Program Pengembangan Produk Unggulan Daerah (PPPUD) yang dibiayai oleh Kemenristek DIKTI selama tiga tahun sejak tahun 2019-2021 untuk menyelesaikan permasalahan dari mitra ini.

Pentingnya tim akademisi UNILAK untuk turut memajukan UKM Wajik Tapai Melayu ini karena produk ini merupakan produk unggulan daerah Propinsi Riau seperti yang telah diatur dalam PP dalam negeri Nomor 9 tahun 2014 (Sudiar, 2019) sehingga mampu membantu UKM menjadi lebih berkembang. Dengan adanya akademisi ikut berperan dalam kegiatan PKM dapat membantu mitra untuk menyelesaikan permasalahannya, namun tidak semuanya sesuai dengan apa yang diinginkan oleh mitra seperti hasil penelitian yang dilakukan oleh (Maryanti et al., 2020) dimana dalam riset tersebut terungkap bahwa dosen hanya membingkai situasi agar sesuai dengan kemampuan dan keahlinya, akibatnya perlakuan yang didampingi kepada mitra justru tidak relevan untuk meningkatkan kinerja usaha mikro kecil. Ini sangat disayangkan karena akan berdampak terhadap tidak maksimalnya dalam penyelesaian permasalahan untuk mitra salah satunya adalah memajukan usaha mitra itu sendiri.

Usaha Wajik Tapai Melayu ini sangat berpotensi untuk dikembangkan karena wilayah Siak Hulu merupakan penghasil ubi kayu yang merupakan bahan baku utama dari produk wajik tapai melayu ini, sehingga yang terbantu bukan hanya UKM wajik tapai melayu tapi masyarakat setempat juga memperoleh manfaat yang cukup besar dengan semakin maju dan berkembangnya usaha wajik tapai melayu ini. Ubi kayu masih menjadi primadona sebagai bahan baku makanan hal ini disebabkan banyak produk yang dapat dihasilkan dari ubi kayu salah satunya adalah dengan mengolahnya menjadi tepung Mocaf (Modified Cassava Flour), disamping itu ubikayu merupakan tanaman rakyat yang dapat dikatakan makanan pokok selain nasi oleh masyarakat Indonesia. Hampir semua dari ubi kayu dapat dimanfaatkan atau dikonsumsi, sehingga potensi dari tanaman singkong ini sangat beraneka ragam dani kaya akan manfaat. Bila digunakan sebagai penganan dapat diolah menjadi keripik, kudapan, sayuran, tape, cake, puding, roti atau berbagai hidangan lezat lainnya. Berbagai aspek perlu diperhatikan dalam upaya mengembangkan agroindustri berbasis pangan lokal. Ketersediaan bahan baku yang merupakan sumberdaya lokal merupakan faktor utama. Faktor lain yang perlu dipertimbangkan adalah teknologi pengolahan, sumberdaya manusia, pasar, dan kebijakan pemerintah (Maryanti et al., 2018).

Ada beberapa hal yang harus diperhatikan ketika akan membantu UKM dalam memajukan usahanya yaitu:(Umasugi, 2012)

1. Memberdayakan peran pemerintah kepada UKM melalui emndampingi UKM dan mempersiapkan UKM trade center

2. Menghilangkan kesan bahwa UKM untuk yang berpendidikan rendah

3. Diperlukannya pelatihan untuk mengubah pola fikir UKM untuk memajukan usahanya

4. Diperlukannya tenaga pendamping untuk mempersiapkan UKM siap mandiri, UKM berbasis kualitas. 


\section{METODE}

Untuk dapat membantu mitra dala menyelesaikan permasalahannya maka tim menggunakan beberapa metode yaitu:

\section{Pelatihan}

Dalam pelatihan ini tim mecoba menyelesaikan permasalahan yang dihadapi mitra terkait dengan kualitas produk wajik tapai melayu yang memiliki tekstur mudah mengeras sebelum habis masa kadarluarsanya. Melalui pelatihan ini tim mendatangkan tenaga ahli yaitu Prof Usman Pato yang merupakan pakar dibidang pangan dan banyak penelitian serta kajiannya terkait dengan kualitas pangan. Adapun upaya yang dilakukan untuk mengatasi kualitas produk dari wajik tapai melayu tersebut maka perlakuan terhadap adonan wajib di perhatikan seperti dengan memperhatikan udara yang masuk pada saat mengemas produk, agar kualitas produk tidak mudah mengeras maka di berikan penambahan zat Stabilex BR (Pati Termodifikasi) yang berungsi untuk membuat adonan tidak mudah mengeras namun zat ini diperbolehkan digunakan untuk produk makanan karena bahan bakunya juga berasal dari organic.

Disamping itu juga memberikanpelatihan terkait penggunaan alat untuk mengaduk adonan wajik tapai yaitu Mesin Evaporator Kristalisasi agar mempermudah dan memeprcepat dalam proses pengadukkan adonan yang awalnya 5 jam untuk mengaduk $6 \mathrm{~kg}$ adonan wajik tapai yang menghasilkan 3,5 kg adoanan wajik tapai yang siap jadi. Mitra menggunakan kompor yang berbahan bakar minyak tanah untuk proses pengadukannya.

Sedangkan terkait kemasan produk yang selama ini memakan waktu yang cukup lama dalam pengemasan dan kurang efisiennya konsumen saat mengkonsumsi produk tersebut, maka tim mencoba untuk mendesain ulang kemasn dari wajik tapai melayu sehingga lebih efisien dan efektif saat proses pengemasan maupun pada saat konsumen mengkonsumsinya. Desain ulang kemasan wajik tapai ini dilakuakn untuk menekan biaya produksi yang di keluarkan oleh mitra wajik tapai melayu.

\section{Pendampingan}

Bentuk pendampingan yang diberikan kepada mitra adalah dengan selalu melakukan kunjungan ke tempat mitra untuk melihat hasil dari penggunaan mesin Evaporator Kristalisasi , apakah berfungsi dengan baik atau tidak jika tidak berfungsi dengan dengan maka tim akan melakukan perbaikan terhadap mesin tersebut. Disamping itu tim juga melakukan pendampingan terkait penggunaan zat Stabilex BR ( Pati Termodifikasi) apakah hasilnya sesuai dengan yang diharapkan agar produk tahan lama dan bertekstur lembut.

\section{Evaluasi}

Untuk mengevaluasi kegiatan ini maka tim bergantian untuk turun ke mitra minimal dalam satu minggu ada 1 org tim yang turun untuk melakukan evaluasi . Disamping itu tim juga akan melakuakn pencatatan perolehan keuntungan yang diperoleh mitra terkait adanya perubahan kemasan dan kualitas produk wajik tapai melayu yang telah menggunakan zat Stabilex BR ( Pati Termodifikasi). Lalu tim yang lain juga memantau respon pasar terkait perubahan dari produk wajik tapai melayu minimal dalam satau bulan ada 3 orang tim yang saling bergantian untuk melakukan survey pasar, apakah konsumen menyukai tampilan baru dari kemasan wajik tapai atau tidak dan apakah konsumen merasakan perbedaan kualitas produk dari wajik tapai melayu tersebut.

\section{HASIL DAN PEMBAHASAN}

a) Tahapan Evaluasi Uji Coba Penggunaan Serat Stabilex BR

Berdasarkan saran dari Prof Usman Pato selaku tenaga ahli pangan menyarankan untuk memberikan serat dengan nama Stabilex BR (Pati Termodifikasi) untuk dapat mengikat air yang 
ada didalam adonan tersebut sehingga kualitas dari adonan wajik tersebut bisa berstekstur lembut dan tahan lama. Pada saat melakukan uji coba tersebut setiap adonan ditandai dengan tanggal dan diberikan catatan perubahan setiap minggunya sampai jangka waktu 3 bulan.
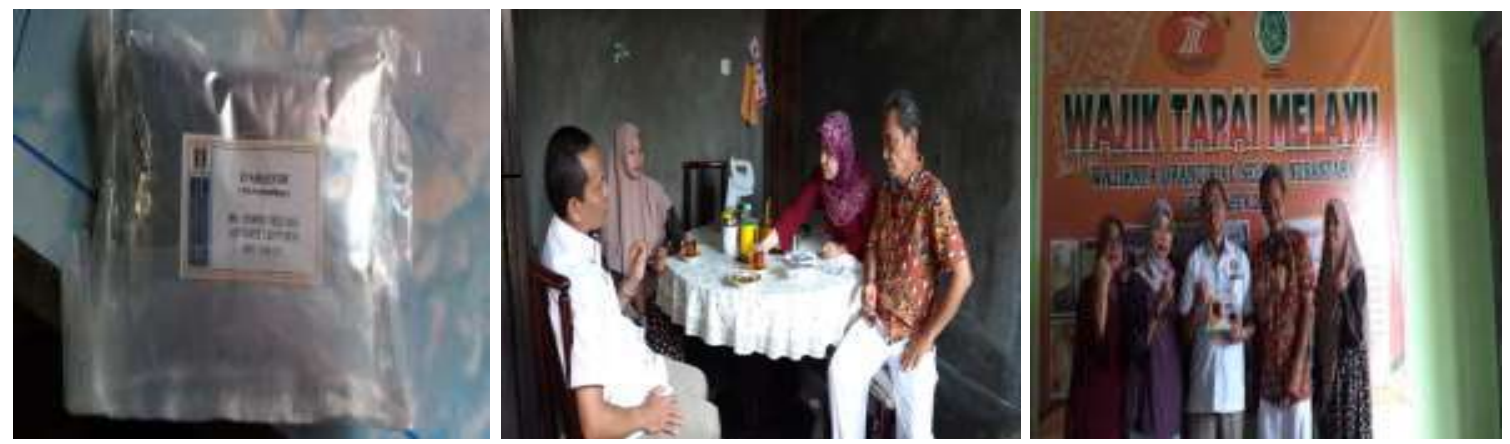

Gambar 1 . Prof Usman Pato Melakukan kunjungan dan melakukan uji coba Penggunaan Serat Stabilex BR ke adonan Wajik tapai

Dari hasil percobaan tersebut diperoleh hasil bahwa uji coba menggunakan serat tersebut tidak memperoleh hasil maksimal, dimana adonan yang menggunakan serat dengan masa uji coba 1 bulan , 2 bulan memiliki tekstur yang agak keras dan warna yang dihasilkan cenderung memudar terkait rasa dari adonan tersebut cenderung lebih apek. Menurut Prof. Usman Pato hal ini terjadi disebabkan bentuk kotak atau wadah penyimpanannya masih belum kedap udara sehingga dengan kotak penyimpanan seperti itu akan memudahkan oksigen masuk sehingga bakteri lebih cepat melakukan pembusukkan terhadap makanan tersebut. Tahapan selanjutnya yang dilakukan oleh Prof Usman Pato adalah menyimpan adoan yang telah dikemas dalam kemasan yang kedap udara agar menghasilkan produk yang lembut untuk masa 3 bulan sebelum masa kadaluarsa habis.
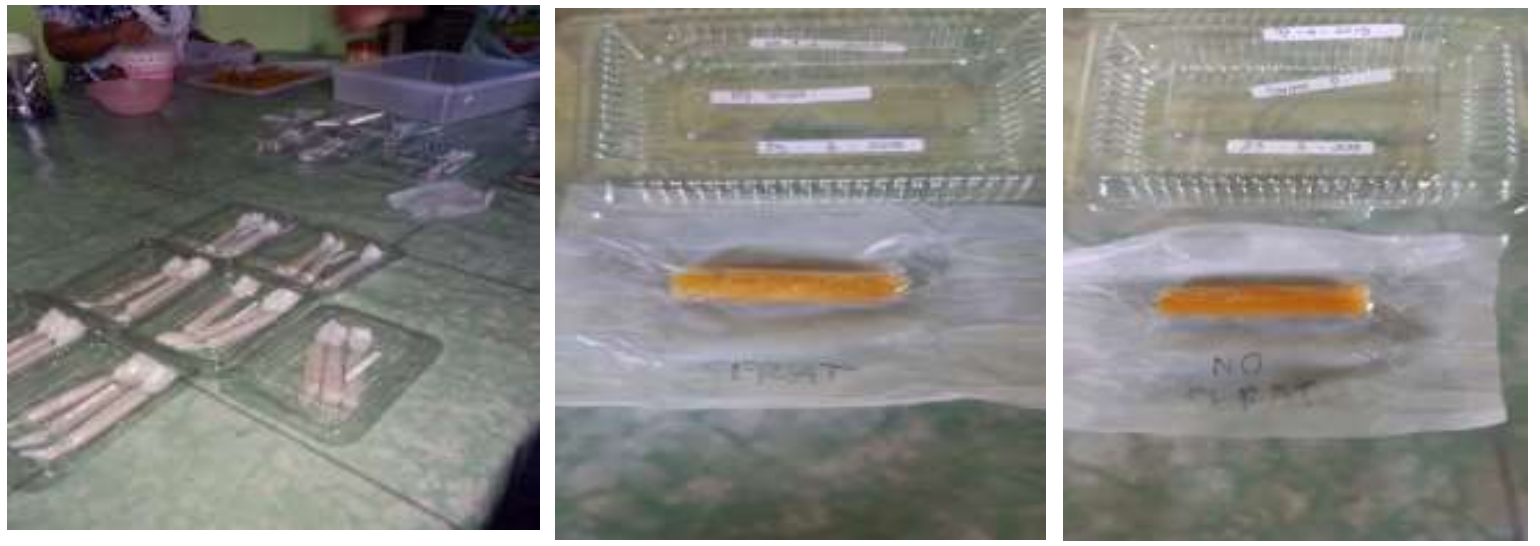

Gambar 2. Hasil percobaan adonan wajik tapai yang menggunakan

\section{b) Tahapan Evaluasi Uji Coba Penggunaan Mesin Evaporator Kristalisasi}

Untuk mengatasi permasalahan yang dihadapi mitra yaitu waktu membuat adonan wajik tapai masih secara konvensional menggunakan tenaga manusia sehingga memakan waktu yang cukup lama, dimana untuk enam kilo adoanan memakan waktu hampir 5 jam . oleh karena itu tim PPPUD memberikan mesin yang dapat digunakan untuk mempersingkat waktu untuk proses produksi . Dari perbandingan waktu antara konvensional dengan menggunakan mesin lebih menghemat waktu sekitar 2 jam dengan jumlah adonan yang sama, artinya banyak yang bisa digunakan dari kelebihan waktu kelebihan tersebut. 

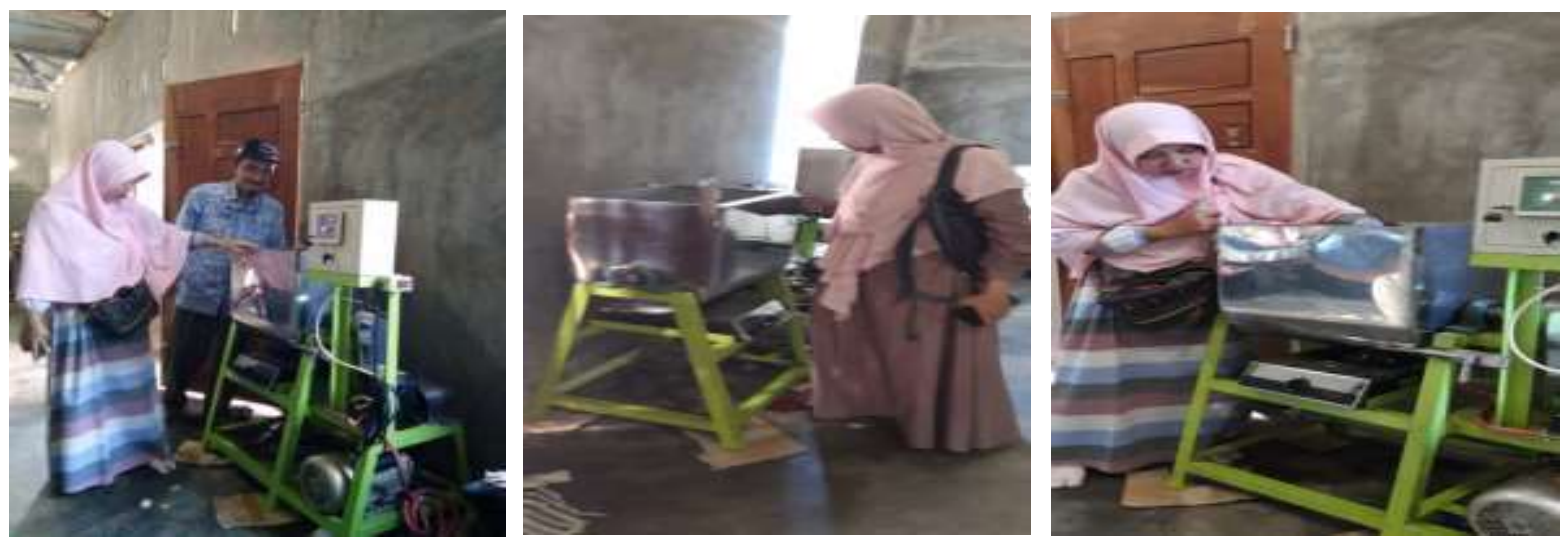

Gambar 3. Mesin Pengaduk Adonan Wajik Tapai Telah sampai Ke tangan Mitra PPPUD

Setelah dilakukan uji coba dengan mesin tersebut menurut mitra PPPUD mesin tersebut sangat membantu karena mampu menampung dan memproduksi adonan 3 kali lebih banyak dari yang sebelumnya. Pada saat masih menggunakan cara konvensional mitra PPPUD hanya mampu memproduksi $6 \mathrm{~kg}$ adonan sehingga dalam satu minggu harus memproduksi beberapa kali untuk memenuhi permintaan pasar akan wajik tapai tersebut. Bahkan dalam satu hari bisa memproduksi beberapa kali hal tersebut disesuaikan dengan kapasistas penyimpanan yang dimiliki oleh mitra PPPUD. Jika lemari penyimpan masih penuh maka produksi dihentikan terlebih dahulu dan biasanya di fokuskan utnuk membungkus adonan ke dalam kemasankemasan yang telah disediakan, ini tentu membuang waktu dan biaya yang sangat membebani mitra PPPUD.

\section{c) Tahapan Me-Redesain Kemasan Wajik Tapai}

Untuk membuat kemasan produk Wajik Tapai Melayu ini mencoba mendsain ulang kemasan yang telah ada sebelumnya agar dapat memenuhi kriteria ekspor produk dengan melakukan perbaikkan dibeberapa item . Pada tahap ini untuk mendisain kemasan baru sampai pada tahap merancang kemasan yang baru dengan logo yang baru pula karena logo dari kemasan yang lama belum necirikan produsen dari wajik tapai melayu. Dalam perancangan kemasan ada beberapa hal yang harus diubah oleh tim PPPUD yaitu dari sisi tampilan warna dan kualitas kemasan produk. Namun ada beberapa yang harus jadi pertimbangan tim PPPUD yaitu dari sisi tampilan warna dan kualitas kemasan produk. Namun ada beberapa yang harus jadi pertimbangan tim PPPUD yaitu tampilan kemasan hendaknya tidak membuat identitas dari wajik tapai melayu tersebut hilang, sehingga konsumen lebih mudah mengenalnya.

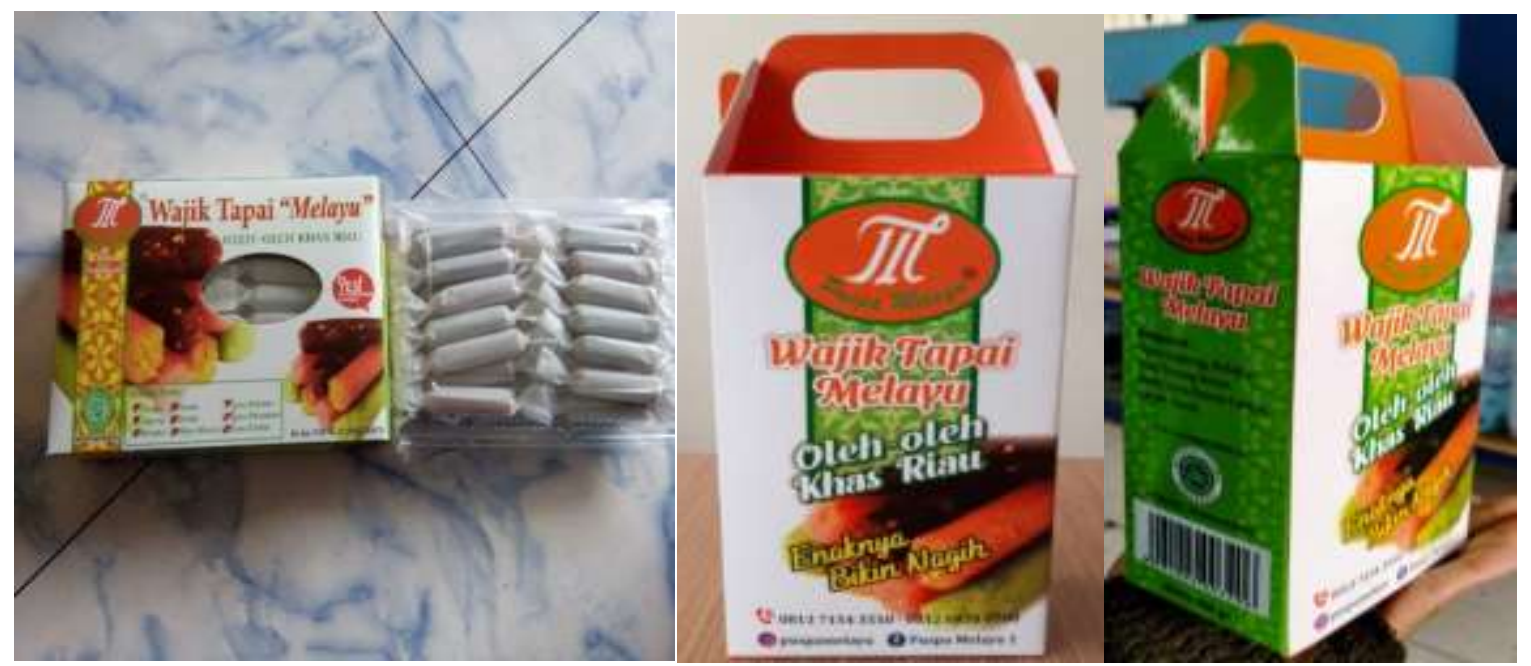

Gambar 4. Bentuk Kemasan Wajik Tapai Melayu yang lama (Kiri) dan Baru (Kanan) 
Dalam pembuatan kemasan produk ini Tim PPPUD ingin mengubah bentuk kemasan yang ramah lingkungan dan lebih simple saat mengkonsumsi yaitu dengan memperhatikan kualitas kemasan wajik tapai. Hal ini disesuaikan dengan aturan internasional untuk ekspor produk. Untuk dapat menembus pasar ekspor maka tim PPPUD akan mencoba mengajukan permohonan untuk mendapatkan eco label dari KEMENLHK ( Kementrian Lingkungan Hidup) melalui Pusat Standarisasi Lingkungan dan Kehutanan dengan melalui websitenya http:// standardisasi.menlhk.go.id, pada tahapan ini tim PPPUD sedang melakukan pengajuan dengan melakukan kontak dengan Lembaga Sertifikasi Ekolabel (LSE) yaitu Balai Besar Pulp dan Kertas yang memiliki ruang lingkup kertas kemas.

\section{d) Tahap Analisis Untuk Omset dan Peningkatan Kualitas Produk Wajik Tapai Melayu}

Omset merupakan total pendapatan yang dihasilkan dari seluruh penjualan produk atau jasa dalam kurun waktu tertentu. Total pendapatan tersebut belum dikurangi HPP (Harga Pokok Penjualan) dan biaya-biaya (listrik, air, gaji, perlengkapan dsb). Bisa dikatakan omset adalah laba kotor yang dihasilkan setiap usaha.

\section{Omset = Jumlah Produk yang terjual X Harga Pokok}

Sebelum kegiatan PPPUD jumlah produk wajik tapai melayu yang terjual tiap bulannya sebanyak 20.000 kotak dengan harga pokok Rp 25.000 berarti omset wajik tapai melayu $\mathrm{Rp}$ 500.000.000. Setelah diadakannya kegiatan PPPUD jumlah produk yang terjual 40.000 kotak dengan harga pokok Rp 25.000 maka omset wajik tapai melayu Rp 1.000.000.000 perbulan.

Peningkatan omset ini terjadi karena mitra telah menggunakan mesin pengaduk dodol sehingga proses produksi memakan waktu yang lebih singkat. Disamping itu untuk kualitas produk yang dihasilkan oleh mitra sebelumnya wajik tapai memiliki tekstur yang keras sebelum sampai masa kadaluarsa namun setelah menggunakan Stabilex BR kualitas produk dari wajik tapai melayu memiliki tekstur yang lembut sebelum masa kadaluarsa sehingga jumlah produk wajik tapai melayu yang di retur sebelum adanya Stabilex BR biasanya mencapai $20 \%$ dari jumlah produk yang dipasarkan berarti jika produk yang terjual 20.000 kotak diretur $20 \%=$ 4.000 kotak yang harus ditarik X Rp 25.000 = Rp 100.000.000 kerugian yang harus ditanggung oleh mitra. Namun sejak menggunakan Stabilex BR jumlah retur hanya 5\% dari jumlah produk yang terjual . Jika produk yang terjual 20.000 kotak X 5\% $=1.000$ kotak yang diretur X Rp 25.000 $=\mathrm{Rp} 25.000 .000$ kerugian. Jika Produk yang terjual 40.000 kotak dengan retur $20 \%=8.000$ kotak maka kerugian yang diderita oleh mitra Rp 200.000.000 dan jika retur $5 \%=2.000$ kotak maka kerugian sebesar Rp 50.000.000. Artinya dengan adanya kegiatan PPPUD ini mitra sangat terbantu dalam berusaha terutama dalam peningkatan kualitas produk dan proses produksi yang dapat dipersingkat.

\section{KESIMPULAN}

1) Produk yang dihasilkan oleh mitra PPPUD selama ini diproduksi dengan cara konvensional sehingga memakan waktu yang cukup lama tapi produk yang dihasilkan tidak banyak sesuai dengan permintaan pasar karena keterbatasan tenaga. Hal ini dapat ditasi dengan menggunakan mesin Evaporator Kristalisasi untuk mengaduk adonan dalam jumlah yang besar.

2) Produk yang dihasilkan oleh mitra PPPUD memiliki tekstur yang mudah keras seblum masa kadaluarsanya tiba, hal ini sangat merugikan mitra PPPUD karena harus meretur produk mereka kembali dan produk yang sudah keras tersebut hanya bisa di konsumsi oleh pegawai dari mitra PPPUD. Untuk mengatasi maslah ini tim PPPUD meminta bantuan tenag ahli pangan dari Universitas Riau Prof. Usman Pato, dimana Prof Usman Pato melakukan uji coba menggunakan Serat Stabilex BR untuk mengikat air yang ada didalam adonan wajik tapai 
tersebut. Namun masih muncul kendala karena produk masih keras dan cenderung berubah rasa . Percobaan kembali dilakukan oleh Prof. Usaman Pato dengan memeprbaiki bentuk kemasan menjadi kedap udara sehingga tidak ada oksigen yang masuk dan hasilnya produk wajik tapai melayu memiliki tekstur yang lembut sebelum masa kadaluarsa tiba.

3) Kemasan produk dari wajik tapai melayu telah dilakukan perubahan dari bentuk yang lama, diamana untuk mengemasnya tenaga kerja dari wajik tapai melayu membutuhkan waktu yang cukup lama karena ada lima tahapan yg harus di lakukan untuk proses pengemasan. Dengan adanya kegiatan PKM skim PPPUD ini mitra di mudahkan dalam mengatasi maslahnya sehingga keamsan wajik tapai melayu yang baru lebih efisien dan efektif dari proses pengemesan hingga proses konsumsi ditangan konsumen.

\section{UCAPAN TERIMA KASIH}

Penulis mengucapkan terima kasih kepada Direktorat Riset, Dan Pengabdian Masyarakat DIrektorat Jenderal Penguatan Riset Dan Pengembangan Kementrian Riset dan Teknologi / Badan Riset dan Inovasi Nasional yang telah memberi dukungan financial terhadap pengabdian ini dalam SKIM Program Pengembangan Produk Unggulan Daerah sesuai Dengan Kontrak Penelitian Nomor : 015/LL10/AM/2020

\section{DAFTAR PUSTAKA}

Buku Panduan Penelitian dan Pengabdian Kepada Masyarakat Edisi XIII,(2020), Direktorat Riset dan Pengabdian Masyarakat, KEMENRISTEK DIKTI

Maryanti, S., Suci, A., Sudiar, N., \& Hardi, H. (2020). Root Cause Analysis For Conducting University ' s. Jurnal Mananjemen Dan Kewirausahaan, 22(2), 152-160. https://doi.org/10.9744/jmk.22.2.152

Maryanti, S., Wiyati, R., Thamrin, M., Ekonomi, F., Lancang, U., Mocaf, T., Usaha, A., \& Ekonomi, P. (2018). PEKANBARU. 1, 1638-1653.

Sudiar, N. (2019). Konsep OVOP Untuk Mengidentifikasi Produk Unggulan Daerah (Studi Kasus Wajik Tapai Melayu). Dinamisia: Jurnal Pengabdian Kepada Masyarakat. https://doi.org/10.31849/dinamisia.v3i0.2864

Umasugi, L. (2012). Pendekatan dinamis dalam pengembangan UKM di Kota Ternate. Agrikan: Jurnal Ilmiah Agribisnis Dan Perikanan. https://doi.org/10.29239/j.agrikan.5.1.15-23 